\title{
O padrão de mobilidade de São Paulo e o pressuposto de desigualdade
}

Patricia Zandonade. Universidade Federal do ABC, São Paulo, Brasil. Ricardo Moretti. Universidade Federal do ABC, São Paulo, Brasil.

RESUMEN | Os fatores determinantes dos problemas de mobilidade cotidiana nas metrópoles brasileiras estão associados ao seu padrão desigual de urbanização. Tomado como referência para esta discussão, São Paulo é um caso de extrema representatividade para esta problemática, onde as dificuldades de mobilidade afetam seriamente a população de menor renda. Mais recentemente o problema se alastra e crescem as pressóes pela melhoria das condições de transporte. Neste contexto, o debate sobre melhoria dos sistemas de transporte coletivo é necessário, mas não suficiente. A expectativa de utilização do automóvel particular é generalizada, porém não existem condições de viabilizar a mobilidade cotidiana com base nesse modal. A ampliação do transporte sobre trilhos é lenta e não há possibilidade de mudança substantiva em curto prazo. Este caótico modelo sustenta-se no pressuposto da desigualdade social, que resulta hoje numa crescente desigualdade ambiental urbana. A melhoria das condições de mobilidade para todos envolve o questionamento desse pressuposto.

PALABRAS CLAVE | desigualdade social, modelos de transporte, transporte urbano.

ABSTRACT | The inequality pattern of urbanization is a crucial factor determining problems of daily mobility in metropolitan areas. Sao Paulo is a representative case study since the problems of mobility long since are deeply affecting the low income population. More recently the problem is gaining scale and pressure for improved transport conditions are growing. In this context, discussing measures to improve public transport systems is necessary but not sufficient. The dream of car ownership and use is widespread, but this modal shift has no conditions to enable daily mobility. The expansion of rail transportation system is slow and in this context there is no possibility of substantive change in the short term. The current chaotic mobility model is structured by the social inequality, resulting nowadays in a growing urban environmental inequality. Mobility improvement for everyone requires deconstruction of the inequality pattern.

KEY WORDS | social inequalities, transportation models, urban transportation.

Recibido el 26 de junio de 2010, aprobado el 9 de diciembre de 2010.

E-mail: Patricia Zandonade, patricia.zandonade@ufabc.edu.br | Ricardo Moretti, ricardo.moretti@ufabc.edu.br 


\section{Introdução}

Os conflitos de mobilidade das metrópoles brasileiras têm como pano de fundo as questões relacionadas ao uso do espaço público. Para o caso de São Paulo, estes conflitos se mostram mais acentuados, onde seu padrão de urbanização se traduz num padrão radicalmente desigual de mobilidade e acessibilidade urbana.

$\mathrm{Na}$ discussão sobre mobilidade, as abordagens ambientais predominantes se articulam em torno do gasto de energia fóssil e sobre a degradação ambiental que o atual modelo de transporte provoca, que se reflete em um aparelho urbano dispendioso, em tempo e recursos. As discussões mais recorrentes abordam os impactos relacionados com a poluição do ar, falta de segurança e adequação dos espaços públicos, poluição sonora, poluição dos solos e das águas com a sujeira das ruas arrastada pelas chuvas.

Porém, as situações críticas de congestionamentos de tráfego e de dificuldades dos deslocamentos na Região Metropolitana de São Paulo têm acontecido em momentos em que uma parcela relativamente pequena dos automóveis do município está em circulação. $\mathrm{O}$ tráfego de veículos praticamente pára, resultando em centenas de quilômetros de congestionamentos, em momentos em que não mais que $16 \%{ }^{1}$ do total de automóveis cadastrados em São Paulo estão na rua. Essa situação assumiu contorno caótico no último período de chuvas. Aqueles que usam o automóvel para seu deslocamento cotidiano reclamam da situação, reivindicando melhorias viárias e eficiência no sistema de circulação, e apontam que a precariedade do sistema de transporte coletivo impossibilita a sua utilização como alternativa ao automóvel.

Pode-se, de início, concluir que não há espaço público disponível para que todos utilizem diariamente o automóvel. O consumo de solo urbano no modelo de mobilidade baseado no automóvel particular é muito maior do que no modelo baseado no transporte coletivo. Se a cidade foi pensada para o carro, então se pressupõe que todos poderiam ter e usar seu carro na cidade para seus deslocamentos cotidianos. Mas o processo de urbanização das metrópoles brasileiras tem como pressuposto a desigualdade ambiental, que integra seu sistema de desigualdades sociais. Enquanto os impactos deste padrão de mobilidade puderem ser repassados para outros grupos sociais, aqueles que se beneficiam do modelo não têm grande interesse em mudanças significativas. A preocupação do amplo acesso do automóvel às classes sociais antes sem possibilidade é anacrônica se não for considerado esse quadro. Questiona-se assim a abordagem simplificada do tema, que focaliza de forma isolada a perspectiva dos investimentos em estruturas viárias e técnicas dos sistemas de transporte coletivo.

\section{Urbanização dispersa e características da metrópole contemporânea}

A metropolização e a dispersão urbana tornaram o sistema de mobilidade, que antes era secundário na relação e definição entre as formas de moradia e formas de trabalho, em um elemento estruturador destes sistemas no tecido urbano. As

\footnotetext{
Segundo estudo de Cardoso, nos horários de pico em São Paulo circulam em uma hora nas ruas em torno de 840 mil automóveis ou um total de 1 milhão de veículos. Sobre esta pesquisa, ver reportagem da Folha de São Paulo de 26 de outubro de 2009, ou o artigo Cardoso (2009b)
} 
mudanças no sistema de mobilidade se inserem neste processo de transformação e adaptação às novas realidades e também ao novo ciclo econômico do contexto nacional, desencadeado na segunda metade do século passado. Este processo trouxe impactos sociais e ambientais, que resultaram na alteração dos padrões de deslocamento cotidiano, alterando modos de circulação, gestão do transporte e do trânsito, e desencadeando novas configurações do tecido urbano.

Quando falamos de mobilidade urbana estamos falando do tecido urbano dinâmico, onde a moradia não pode ser considerada um ponto fixo e a realidade metropolitana segue em contínuo processo de mudanças. A urbanização dispersa da metrópole reforçou a dinâmica que relaciona fortemente as condiçôes de moradia, trabalho e renda, e as formas de circulação. A mobilidade na metrópole não pode ser considerada aleatória, a partir de uma escolha individual, e a transformação do tecido urbano disperso se insere numa lógica de reestruturação das formas de habitar, de produzir, de se deslocar e de organizar a vida cotidiana. Juntamente com este processo, verificam-se como características da metrópole brasileira, e igualmente das demais latino-americanas, o aumento constante do crescimento de precárias periferias residenciais de baixa renda e a proliferação de porções auto-segregadas de residências de mais alta renda, assim como a acessibilidade desigual às oportunidades e amenidades urbanas.

Algumas características deste novo modelo territorial, relacionado com a expansão da mobilidade ocorrida a partir da década de 70 , incluem uma expansão física sem precedentes, a fragmentação, especialização e complexidade crescente do espaço urbano (García Palomares, 2008). Nos espaços metropolitanos as transformaçôes territoriais e sociais criam necessidades de se alcançar um número maior de destinos para uma variedade maior de atividades, agora mais dispersos e distantes. O desenvolvimento dos meios de transporte e comunicações alarga as distâncias cotidianas, multiplicando as possibilidades de escolha para uma parte da população: o lugar da residência, a localização do trabalho, as relações pessoais, todos a partir de uma multiplicidade da mobilidade (Ascher, 1995).

A descentralização também segue com a implementação de novos espaços de atração na periferia, induzindo e sendo induzidos por este processo de dispersão, como grandes centros de consumo, serviços do terciário avançado, centros de lazer, centros complexos de residência, lazer e serviços, etc. Para o caso das metrópoles do hemisfério sul mantêm-se nos centros tradicionais espaços de atração de viagens, tornando complexo também o entendimento dos fluxos e dinâmicas de viagens centro-periferia.

As oportunidades geradas pela economia metropolitana são melhores aproveitadas com o incremento da capacidade de deslocamentos cotidianos. Grupos de população com maior nível de renda e capacidade de deslocamentos aumentam suas oportunidades econômicas, enquanto que os grupos de mais baixa renda, cada vez mais numerosos, são submetidos a uma desigualdade de mobilidade e acesso à cidade, que tornam suas oportunidades econômicas ainda mais reduzidas. Assim, associa-se um processo de desigualdade social à desigualdade ambiental nas metrópoles. 
A mudança das relações de apropriação do espaço é outro ponto chave e dialético na percepção dos problemas ambientais urbanos. O bairro deixa de ser a unidade urbana da proximidade e os guetos que vão se formando passam a estruturar pequenas comunidades. Esta fragmentação acontece tanto para as camadas de maior renda, a partir dos condomínios fechados e em um processo de auto-segregação, quanto para comunidades de baixa renda, segregadas do restante da cidade pela condição precária dos seus assentamentos. A desigualdade ambiental se acentua com o avanço deste novo padrão de apropriação do espaço urbano.

Assim, o desenvolvimento urbano disperso caracterizado por descontinuidades físicas e territoriais marca a nova estrutura espacial urbana. Este novo tecido, desmembrado e esgarçado só pode ser recomposto e viabilizado a partir do incremento de seus fluxos e o sistema de mobilidade é o estruturante desta nova dinâmica metropolitana. A relação recíproca e circular da estruturação e dos estruturantes destas transformações é o ponto chave para as análises do tema da mobilidade na nova dinâmica metropolitana (Miralles, 2002).

Nesta nova realidade, tem-se um tripé constituído pelos novos padrões de moradia, pelas transformações das relações e espacializações do trabalho, e pela expansão das tecnologias e redes de infraestrutura de deslocamento e transporte. Estas variáveis afetam diretamente as outras dimensões da vida urbana.

FIGURA 1 | Eixos principais do sistema urbano que geram o seu padrão de mobilidade

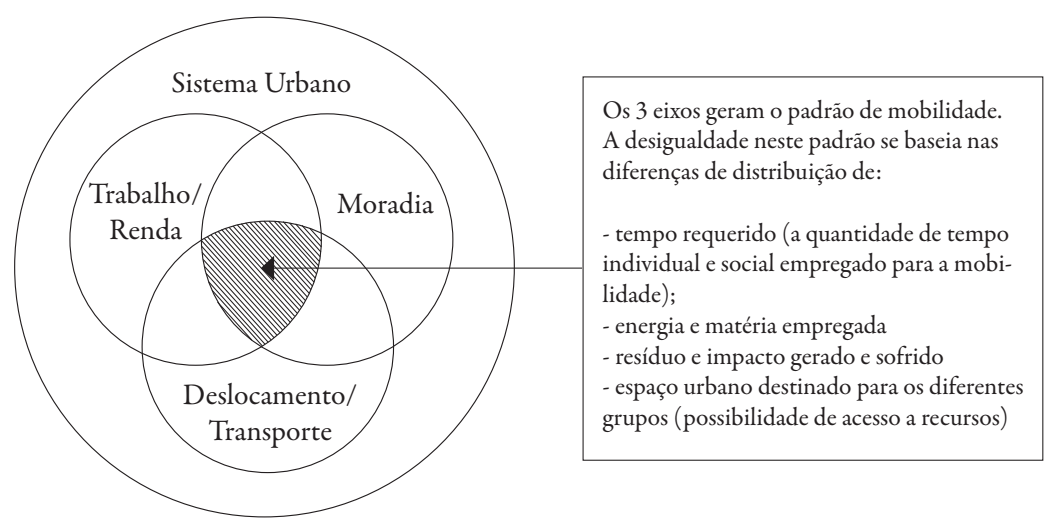

FONTE ELABORAÇão PRÓPRIA.

A melhora nas condições de deslocamento pode gerar possibilidades de melhores postos de trabalho e renda, condições de moradia e inserção na metrópole, melhorando assim sua capacidade de mobilidade. Um acesso à moradia adequada abre a possibilidade de conseguir um bom emprego e renda, melhorando sua capacidade 
de deslocamento e mobilidade, e amplia por sua vez a possibilidade de ter moradia de melhor qualidade. Quanto mais facilitado o acesso ao trabalho decente e à renda, mais fácil se torna o acesso à moradia, ampliando a possibilidade de mobilidade cotidiana e acesso à cidade. Esta abordagem trata das desigualdades setorizadas como incluídas e compondo um sistema. Assim, a desigualdade social é um sistema de desigualdades, que é diminuído a cada inserção positiva em um dos setores, sendo também válida a afirmação para as inserções negativas. A desigualdade urbana se ameniza a cada inserção positiva nos três principais eixos de caracterização do padrão de mobilidade cotidiana - renda/trabalho, moradia, transportes/deslocamentos, e amplia o acesso à cidade. A partir disto se associam outros sistemas de desigualdade, como educação, cultura, consumo, saúde, sendo estes fortemente influenciados pelo tripé moradia/renda/transporte.

Entretanto, em um contexto de sistemas de desigualdade que interagem entre si, é limitado o alcance das ações isoladas no enfrentamento de um problema setorial. Tome-se, por exemplo, a intervenção no sistema de transporte, que pode levar a um resultado contrário ao inicialmente pretendido, com a expulsão dos mais pobres das regiões mais acessíveis. Assim, o que se pretendia como inserção positiva, acaba não se concretizando, por não levar em conta a dinâmica sistêmica dos processos de desigualdade social.

Como um elemento importante nesta discussão, o desenvolvimento da estrutura fundiária das terras urbanas é a base deste sistema de desigualdade ambiental urbana nas cidades brasileiras, definindo as formas de distribuição e apropriação do solo urbano. Este desenvolvimento se deu a partir do pressuposto da desigualdade de acesso à terra entre os diferentes extratos sociais e no desenvolvimento de uma economia estruturada para a concentração de riquezas. Em vários momentos históricos, com a justificativa de estimular o desenvolvimento e a utilização produtiva e rentável do solo - tanto rural como urbano - a transferência de terras anteriormente públicas foi facilitada para aqueles que dispunham de recursos financeiros. Onde antes o escravo era o principal indicador e gerador de riquezas, após a abolição as terras passaram a ser o principal capital sendo mesmo seu valor de propriedade sobreposto ao valor de uso. A terra urbana tem seu valor determinado, sobretudo por sua localização na cidade. A variação deste valor se baseou historicamente nos investimentos e infraestrutura urbana, fazendo com que a proximidade destes equipamentos urbanos gerasse o aumento dos preços da terra. Assim, a criação de núcleos de segregação e distinção social nas áreas urbanas foi uma constante nas cidades brasileiras.

Com a metropolização e a complexificação da dinâmica urbana, associada a novos equipamentos tecnológicos de comunicação e deslocamento, a característica central de valorização imobiliária deixa de ser a proximidade, e passa a ser a acessibilidade. Assim, os equipamentos de deslocamento e transporte urbanos passam a ser os principais orientadores da lógica de valorização imobiliária. Como no Brasil a infraestrutura urbana de deslocamento e transporte é feita pelo estado, este passa 
a ser um parceiro necessário aos capitais para a orientação do valor imobiliário. Esta orientação do valor pelo investimento em infraestrutura tem um efeito mais acentuado nas cidades brasileiras e latino-americanas, onde a regulação do uso e ocupação do solo urbano historicamente acontece para assegurar a qualidade de lugares já valorizados. Aqueles que não possuem ainda este valor comercial elevado pelas infraestruturas não são objeto de fiscalização ou intervenção do estado. Isto acontece porque ao longo da história, e também atualmente, os governos vincularam-se aos interesses daqueles que possuem maior poder econômico. Associado a este contexto, a indústria automobilística e petroquímica foram tomadas como eixos do desenvolvimento industrial brasileiro nos últimos 50 anos. A economia fica assim vinculada à produção e consumo crescente destes artefatos industriais, tendo o automóvel particular como um dos principais setores rentáveis. As políticas de planejamento e projetos urbanos tiveram o automóvel como parâmetro de projeto e de orientação para novas expansões urbanas.

Assim, a vinculação dos grandes poderes econômicos com a governança da cidade é uma fórmula eficiente de orientar a produção de valor da terra e garantir sua apropriação. Para o modelo de deslocamento urbano, o automóvel individual foi a opção historicamente adotada. A simbiose entre o poder do estado e os interesses privados produziu, e ainda produz no Brasil uma desigualdade urbana abissal entre áreas consideradas de ricos e áreas consideradas de pobres, entre o modelo de deslocamento de rico - o automóvel - e o modelo de deslocamento de pobres - o transporte público. As áreas que não possuem 'poder de mercado' não são objeto de preocupação do ponto de vista dos investimentos e melhorias. As regiões de pior capacidade ambiental de urbanização são transferidas para aqueles que não podem pagar o preço de mercado. Em um processo interdependente, as áreas que possuem mais infraestrutura urbana para os deslocamentos, são os lugares ocupados, sobretudo, pelos ricos - que usam majoritariamente o automóvel, e por outro lado, onde moram os ricos, são destinados maiores investimentos em desenvolvimento e manutenção da infraestrutura de deslocamento e transporte coletivo.

Em síntese, destacam-se algumas características da estrutura de São Paulo, que são encontradas também em outras metrópoles latino-americanas:

- O uso do automóvel tem um incremento acentuado e constante e o seu apelo simbólico como representação social é muito forte;

- A mobilidade residencial, traduzida numa migração intraurbana do centro para as periferias precárias, é acentuada. $\mathrm{O}$ preço elevado de moradias nos locais centrais ou com mais infraestrutura faz com que este movimento em direção a áreas periféricas seja cada vez mais intensificado. Para as camadas de menor renda, este movimento tem como destino as áreas menos valorizadas e com menor infraestrutura urbana. Para as classes de maior poder aquisitivo, ocorre a busca por novas formas de moradia, aliando menores densidades e características simbólicas de qualidade de vida e segurança, localizaçóes estra- 
tégicas tanto de acesso a eixos de infraestrutura rodoviária e também de transporte público de massa;

- Os locais de moradia dos trabalhadores são cada vez mais afastados da cidade consolidada e dos empregos formais, e esta característica cria eixos saturados de deslocamento cotidiano;

- Surgem novos artefatos urbanos e empreendimentos privados afastados do centro consolidado, tendo o automóvel como parâmetro de projeto. Esta característica gera espaços coletivos onde seu uso se torna exclusivo das camadas de maior renda e distancia a rua como espaço público e heterogêneo;

- As camadas de menor renda não têm o leque de escolha dos fatores de custo e de tempo nos deslocamentos para as suas opções de moradia. Isto acarreta uma nova forma de desigualdade, onde as pessoas de maior renda moram em uma metrópole dispersa, mas com maior mobilidade, enquanto que as camadas mais pobres moram igualmente em um tecido urbano disperso, marcado pelas grandes distâncias, porém com pouca mobilidade. Assim, as camadas mais pobres, comprometem uma maior parcela de seus rendimentos e de tempo para seus deslocamentos diários.

\section{O círculo vicioso}

A partir da década de 90, as metrópoles brasileiras apresentam a característica de aumento acentuado do uso do automóvel. Acontece o que podemos descrever como círculo vicioso, onde a desigualdade da urbanização e a degradação dos espaços públicos decorrente são cada vez mais reforçadas entre si.

Tomando São Paulo como exemplo, e contrariando o senso comum, encontram-se maiores densidades populacionais em bairros afastadas das áreas centrais com as maiores densidades de emprego. Isto leva a grandes demandas de deslocamento da periferia em direção às áreas centrais da metrópole. Como mostra a Tabela 01, a maioria das viagens motorizadas ainda é realizada em transporte coletivo, predominantemente sobre pneus, que disputa o espaço do sistema viário com os carros e é, portanto, bastante sensível ao aumento do número de automóveis particulares em circulação.

Para as pessoas de mais alta renda, o transporte público não é considerado como opção. As pessoas de classe média - que usualmente almejam o padrão de vida de alta renda - tratam a aquisição do carro como uma conquista. A preocupação das classes dominantes em relação à mobilidade na metrópole se foca assim na sua necessidade de deslocamento e na sua modalidade de transporte.

O padrão de mobilidade desigual segue a lógica do processo de urbanização da metrópole. Para os lugares mais precários, com pouca infraestrutura, o atendimento do transporte público também é precário. Então, quando o cidadão vê a oportunidade de aumentar a sua mobilidade e seu conforto a partir da aquisição do carro, mesmo que isto comprometa boa parte de seu orçamento familiar, ele o faz. Com 
um pequeno aumento da renda individual, aliado a facilidades de financiamento e redução do preço final dos automóveis, como aconteceu nos últimos anos, aumenta também a posse e utilização do automóvel como opção de mobilidade.

TABELA 1 | Evolução das viagens diárias por modo principal na RM de São Paulo

\begin{tabular}{|c|c|c|c|c|}
\hline VIAGENS POR MODO NA RMSP & OD 1997 & $\begin{array}{l}\text { PROPORÇÃO } \\
\text { SOBRE TOTAL } \\
\text { DE VIAGENS } \\
\text { EM I } 997(\%)\end{array}$ & OD 2007 & $\begin{array}{l}\text { PROPORÇÃO } \\
\text { SOBRE TOTAL } \\
\text { DE VIAGENS EM } \\
2007(\%)\end{array}$ \\
\hline $\begin{array}{l}\text { Ônibus (ônibus municipal de Säo Paulo + } \\
\text { onibus municipal de outros municipios }+ \\
\text { onibus metropolitano) }\end{array}$ & 7.055 .628 & 22 & 8.327 .503 & 22 \\
\hline $\begin{array}{l}\text { Demais modos rodoviários (fretados + } \\
\text { escolares + microônibus + vans) }\end{array}$ & 1.071 .912 & 3 & 2.546 .764 & 7 \\
\hline TOTAL DE COLETIVOS RODOVIÁRIOS & 8.127 .540 & 26 & 10.874 .267 & 29 \\
\hline Metrô & 1.697 .245 & 5 & 2.223 .397 & 6 \\
\hline Trem & 648.502 & 2 & 815.177 & 2 \\
\hline TOTAL DE COLETIVOS SOBRE TRILHOS & 2.345 .747 & 7 & 3.038 .575 & 8 \\
\hline TOTAL POR TRANSPORTE COLETIVO & 10.473 .287 & 33 & 13.912 .842 & 37 \\
\hline $\begin{array}{l}\text { Transporte individual (automóvel }+ \text { táxi }+ \\
\text { moto }+ \text { outros })\end{array}$ & 9.741 .311 & 31 & 10.472 .037 & 27 \\
\hline TOTAL POR TRANSPORTE INDIVIDUAL & 9.984 .216 & 32 & 11.254 .668 & 30 \\
\hline $\begin{array}{l}\text { TOTAL GERAL DE VIAGENS } \\
\text { MOTORIZADAS }\end{array}$ & 20.457 .503 & 65 & 25.167 .510 & 66 \\
\hline A pé & 10.812 .241 & 34 & 12.623 .047 & 33 \\
\hline Bicicleta & 162.461 & 1 & 303.828 & 1 \\
\hline $\begin{array}{l}\text { TOTAL DE VIAGENS NÃO } \\
\text { MOTORIZADAS }\end{array}$ & 10.974 .702 & 35 & 12.926 .875 & 34 \\
\hline
\end{tabular}

FONTE Metrô, Pesquisa OD de 1997/2007. 
Com mais automóveis na rua, cresce o número de congestionamentos, que por sua vez afeta diretamente o custo, a frequência, o tempo de viagem, e a condição de conforto dos usuários dos ônibus. $\mathrm{O}$ ônibus demora mais para passar, demora mais para chegar ao seu destino, circula lotado e com custos mais altos. A má qualidade do transporte coletivo e a disputa do espaço da rua com o crescente número de automóveis se associam a um ambiente urbano poluído e agressivo. Assim, aquele que mais sofre os efeitos da opção pelo automóvel é aquele que não possui automóvel, que anda a pé, de bicicleta, e transporte público. Mais uma vez, temos o reforço no incentivo ao uso do automóvel, que tem como característica o isolamento da pessoa em relação às condições ambientais do espaço exterior. No carro, a pessoa se sente em seu espaço privado, com mais conforto, se protege do ruído perturbador da rua, da poluição atmosférica, da má adequação bioclimática dos espaços urbanos - a exemplo das ilhas de calor em São Paulo e das condições precárias das calçadas - e ainda das outras pessoas, em face de uma ilusória sensação de proteção contra a violência. Mais carros nas ruas, e mais ruas para carros, alimentam assim o círculo vicioso.

\section{FIGURA 2 | Círculo vicioso no padrão de mobilidade metropolitano}

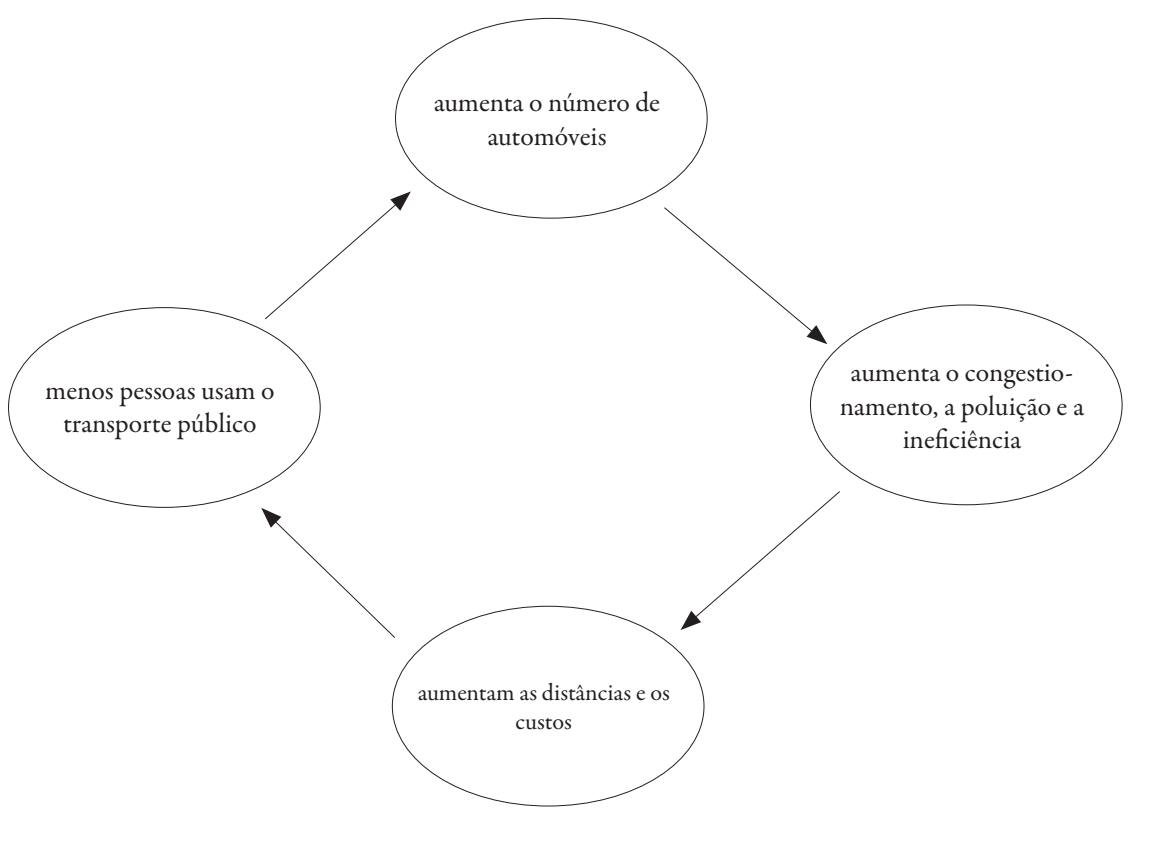

FONTE ANTP, 1997. 
FIGURA 3 | Círculo vicioso no padrão de urbanização e sua relação à mobilidade.)

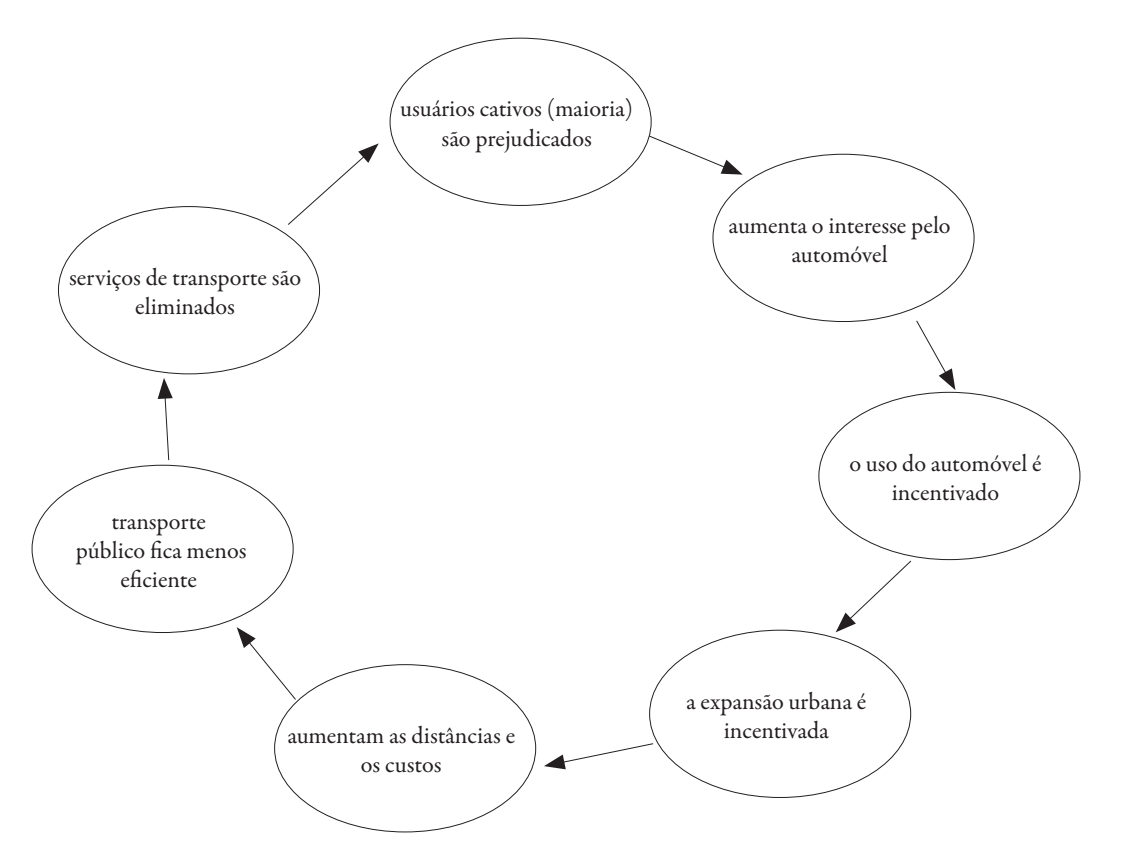

FONTE ANTP, 1997.

\section{O círculo vicioso da desigualdade na mobilidade cotidiana em São Paulo}

O problema dos deslocamentos na cidade vem sendo tratado por uma especialidade de planejamento que nasceu da necessidade de incremento da fluidez do tráfego, pela técnica de planejamentos de transportes desenvolvida pelos Estados Unidos e difundida desde a década de 50.

No Brasil não foi diferente. Estudos de projeção de demanda de sistemas de vias foram posteriormente incorporando outras variáveis, e o planejamento dos transportes públicos passou a ser incorporado pela técnica do planejamento de tráfego. O uso do automóvel passou a ser tomado como uma premissa das políticas urbanas. $\mathrm{Na}$ maioria das metrópoles, e em São Paulo isto é muito mais acentuado, o planejamento de tráfego sempre teve maior abrangência e poder para determinar as prioridades de investimento, em geral focadas na correção da estrutura viária para o tráfego crescente. Historicamente, a solução para os congestionamentos tem sido a construção de mais vias, viadutos, abertura de ruas, e obras de adequação de demanda de tráfego em geral. O sistema de transporte público, que em São Paulo e também nas demais capitais latino-americanas tem o ônibus como principal modalidade, vem a reboque desta orientação, inserida como mais um veículo no cálculo da dinâmica destes fluidos (a Companhia de Engenharia de Tráfego [CET] 
da cidade de São Paulo calcula 1 ônibus equivalente a 2 carros). Nas últimas duas décadas, com o fortalecimento da indústria automobilística na economia do país e os incentivos para este setor, com o sucateamento dos serviços públicos na década de 80 , o crescimento da motorização deu um salto. Agora ter um carro não é um privilégio de elite, é um desejo de todos. Este processo desembocou no quadro atual de verdadeira calamidade da mobilidade urbana paulistana. Então, o modelo mostra sua vertente baseada na desigualdade social: é um modelo criado para beneficiar poucos, e não se pode generalizar.

Fala-se muito do número de veículos emplacados por dia na cidade de São Paulo, onde temos números desde 500 a 1000 carros emplacados por dia para os anos a partir de 2007. Segundo o site do Departamento Estadual de Trânsito de São Paulo (Detran), a frota somente de automóveis particulares na capital em janeiro de 2011 foi de 5.103.295. Em janeiro de 2008 o número era de 4.512.118. ${ }^{2}$

FIgURa 4 | Frota de automóveis que circula a cada hora no município de São Paulo

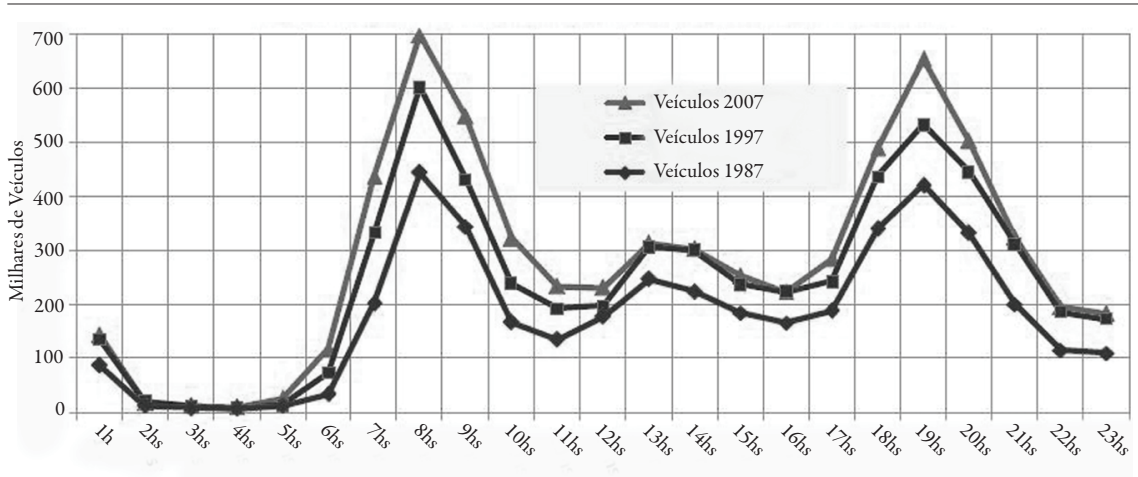

FONTE CARDoso (2009).

FIGURA 5 | Frota de automóveis que circula a cada hora na RM de São Paulo

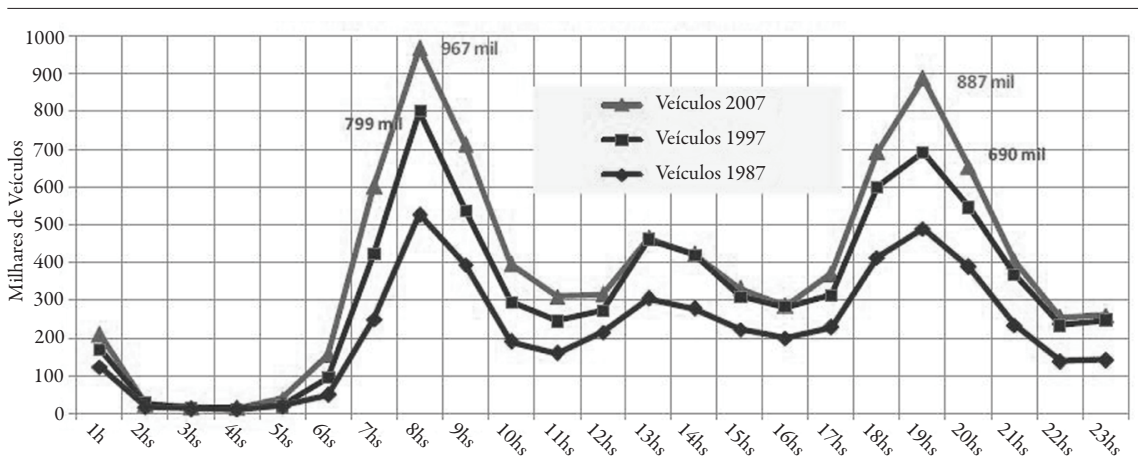

FONTE CARDoso (2009).

2 http://www.detran.sp.gov.br/frota/frota.asp acessado em 15 de setembro de 2009. 
A velocidade média dos carros na capital caiu de 29 para $27 \mathrm{~km} / \mathrm{h}$, de 2006 para 2007, nos horários de pico. Já em 2007, os ônibus se locomoviam com 12 km/h, de acordo com o sindicato SP-Urbanus, de empresas de transporte urbano.

TABela 2 | Frota de automóveis que circula a cada hora em São Paulo

\begin{tabular}{c|c|c}
\hline \multirow{2}{*}{ ANO } & \multicolumn{2}{|c}{ PICOS DE LENTID ÃO - MÉDIA ANUAL EM KM } \\
\cline { 2 - 3 } 2006 & MANHÃ & TARDE \\
\hline 2007 & 86 & 114 \\
2008 & 90 & 128 \\
\hline 2009 (cinco primeiros meses) & 91 & 129 \\
\hline
\end{tabular}

FONTE CET.

Os picos de lentidão praticamente se mantiveram apesar do aumento de $7 \%$ no emplacamento de veículos particulares de passeio a partir do início de 2008. Destaca-se, porém, que o monitoramento limita-se a uma parcela da cidade, concentrado nos setores de maior renda, como pode ser observado quando comparadas as Figuras 11 e 12.

FIGURA 6 | Mapa de fluidez e ocorrências na cidade de São Paulo

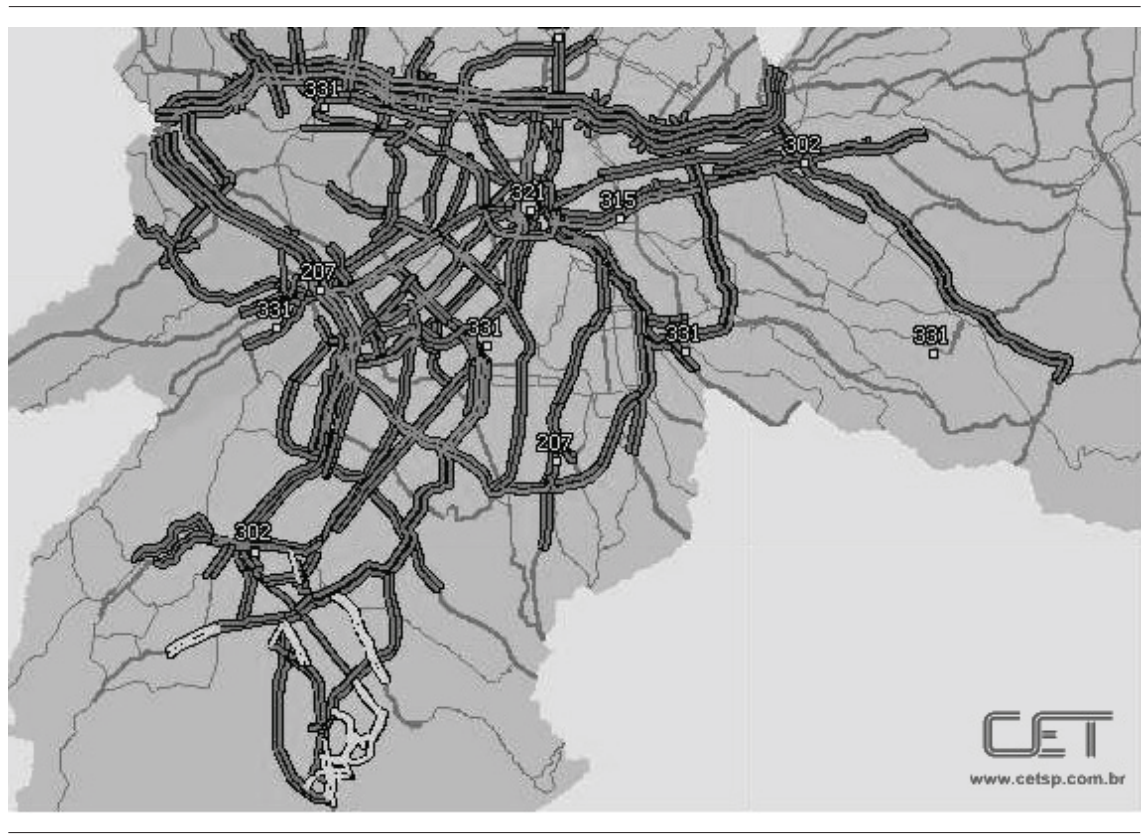

FONTE SITE DA CET (HTTP://CETSP1.CETSP.COM.BR/MONITRANSMAPA/PAINEL/). 
FIGURA 7 | Predominância de população por classes de renda acima de $20 \mathrm{~s} \mathrm{~m}$

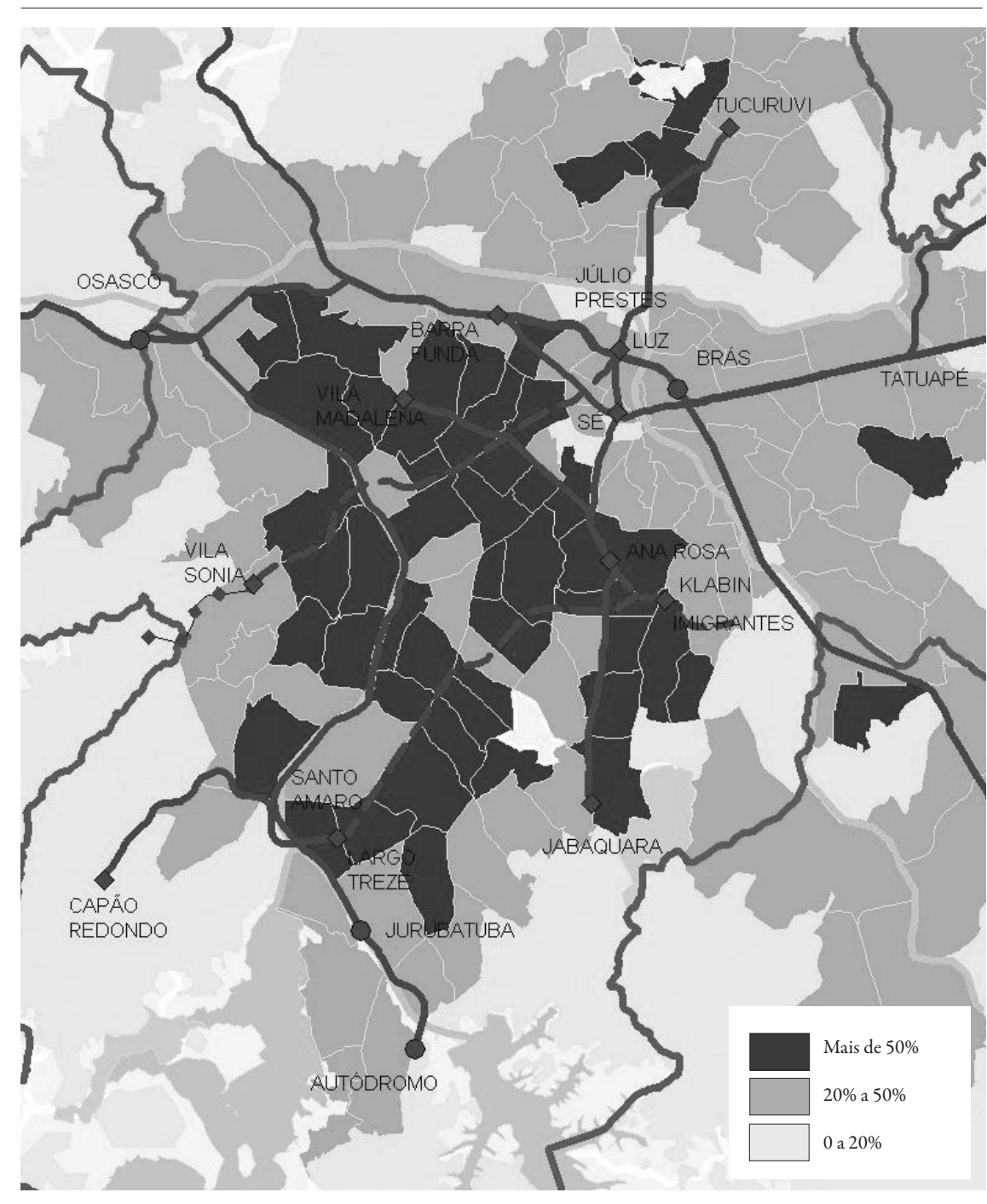

FONTE VillaÇA, F.; Zioni, S. M. (2005).

A capacidade de acomodar veículos nas ruas da São Paulo na área coberta pela pesquisa da CET, ou seja, a zona sudoeste da capital está em seu limite desde 2007, quando se estabilizou a média deste índice. Qualquer evento diferenciado nesta porção que incentive o uso do automóvel particular leva a cidade a ter um grande congestionamento, a exemplo do recorde de $293 \mathrm{~km}$ de lentidão numa tarde de terça feira (10 de junho de 2009), combinando véspera de feriado, acidentes e dia chuvoso. 
FIGURA 8 | Total de moradores por automóvel particular, por distrito

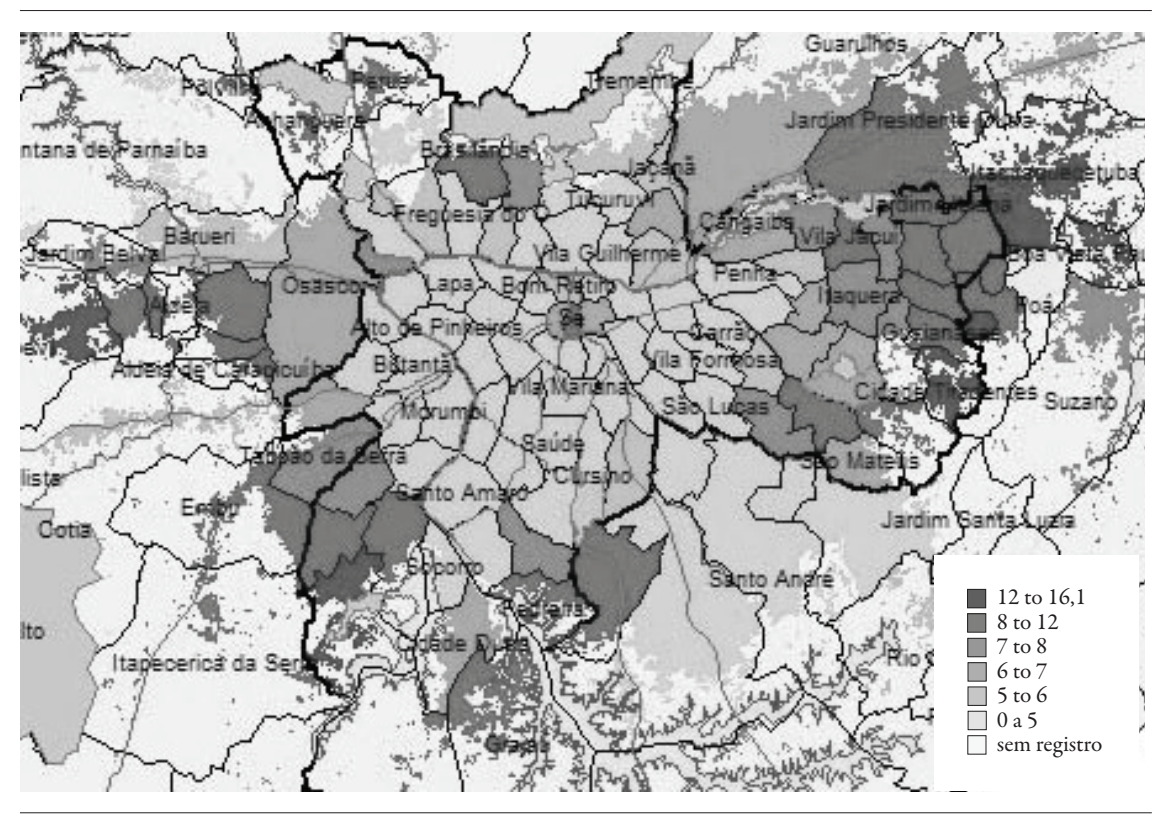

FONTE WWW.NEVUSP.ORG.BR.

Quem precisa mais do carro são as pessoas que moram mais longe da infraestrutura de transporte, que coincide em São Paulo, com as áreas habitadas pelos mais pobres. Quem mora em grandes eixos de transporte, seja uma grande avenida onde podem passar eixos de ônibus de grande capacidade, sejam linhas de trem ou metrô, em geral são pessoas que conseguem pagar o preço da valorização que esta infraestrutura gera para a terra urbana, nas leis de mercado que traduz a dinâmica da metrópole contemporânea. As classes de maior renda tanto moram perto das áreas de maior acessibilidade pelo transporte coletivo ou eixos rodoviários quanto usam predominantemente o transporte individual. Quando menor a renda, mais dependente é do sistema de transporte coletivo. Não é novidade, por exemplo, para nenhum paulistano que, aonde chega o metrô, saem os pobres. A pesquisa de Cardoso (2009a) mostra os dados demográficos de 1997 e de 2007 da Pesquisa Origem Destino do Metrô e revela que a valorização das regiões do entorno das estações de metrô expulsa as famílias mais pobres e abre caminho para a ocupação de famílias menores e que ocupam mais área construída por pessoa, diminuindo a densidade populacional destas localidades.

Em reportagem ao jornal Folha de São Paulo (17-01-10) são apresentados depoimentos de profissionais da área de incorporações imobiliárias onde declaram que o anúncio das obras de uma estação de metrô valoriza imediatamente em 10\% os lançamentos imobiliários próximos, e quando a melhoria urbana é entregue, o valor dos imóveis lançados sobe 30\% a 40\%. 
Esta realidade do acesso à terra e à moradia na estruturação metropolitana também precisa ser colocada na pauta das discussões sobre a mobilidade urbana. Neste contexto está a consolidação do movimento pendular de várias áreas residenciais da periferia da metrópole. Analisando o mapa de densidade de empregos na Região Metropolitana de São Paulo (RMSP) e comparando-o com a densidade demográfi$\mathrm{ca}$, nota-se que todos os dias uma multidão que mora nas periferias precisa sair em horários parecidos (o horário de pico da manhã) de suas moradias e dirigir-se para a região central e sudeste de São Paulo, onde está a maior concentração de emprego.

Figura 9 | RMSP - Densidade de população (hab./ha) 2007 em distritos

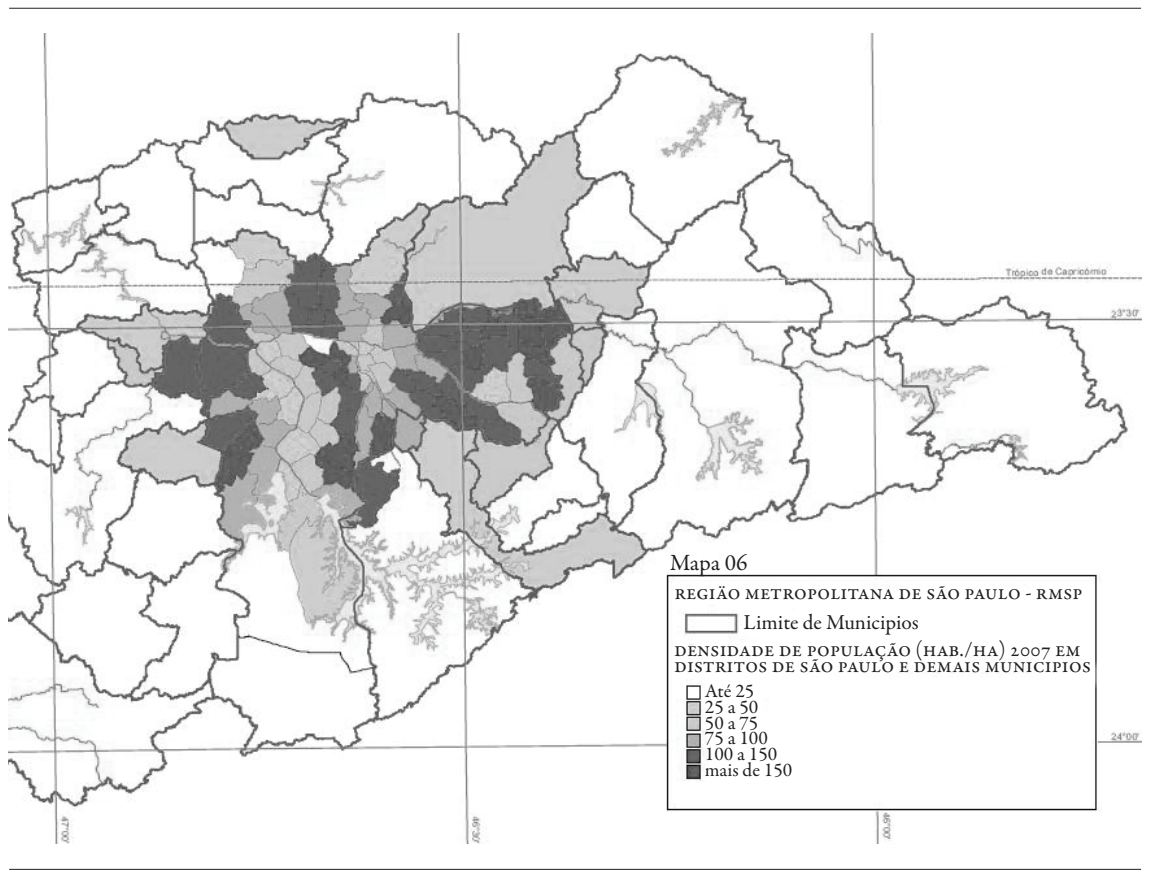

fonte Pesquisa OD 2007 - Síntese das Informações de Pesquisa Domiciliar, Metrô, 2008.

Está também nesta região de maior densidade de empregos uma maior concentração de pessoas de classe de renda média e alta. Na década de 70 , este movimento pendular já demonstrava a saturação dos sistemas de transporte público. Na década de 80, Affonso (1985) fez um balanço desta condição do transporte público desde a década anterior através dos vários movimentos organizados de reivindicação da melhoria do sistema. A precariedade nas formas e características de deslocamento do trabalhador que mora na região do extremo-leste e sul da metrópole é histórica, sendo "o atual caos no trânsito em São Paulo" uma visão recortada deste processo, voltada para as formas de deslocamento da classe dominante. O que desencadeia hoje este discurso do caos da mobilidade em São Paulo é que a demora nos desloca- 
mentos começou a afetar também as pessoas que usam regularmente o carro e circulam pela região centro-oeste, apesar da precariedade das formas de deslocamento das camadas trabalhadoras serem históricas e, ainda hoje, a lentidão afetar muito mais quem usa transporte coletivo. $\mathrm{O}$ sistema que foi construído só pode funcionar se a desigualdade for mantida. Muitos precisam se sujeitar a uma estrutura urbana desigual, a um sistema de transporte saturado e sem prioridade em relação ao automóvel para que outros possam continuar se deslocando rapidamente para se apropriar das oportunidades urbanas. Uma cidade que mede a sua capacidade de transporte pela quantidade de congestionamentos nas vias, como é o caso de São Paulo, claramente mostra onde está seu foco de preocupação: a fluidez do tráfego de automóveis.

Figura 10 | RMSP - Densidade de empregos (empregos /ha) 2007 em distritos

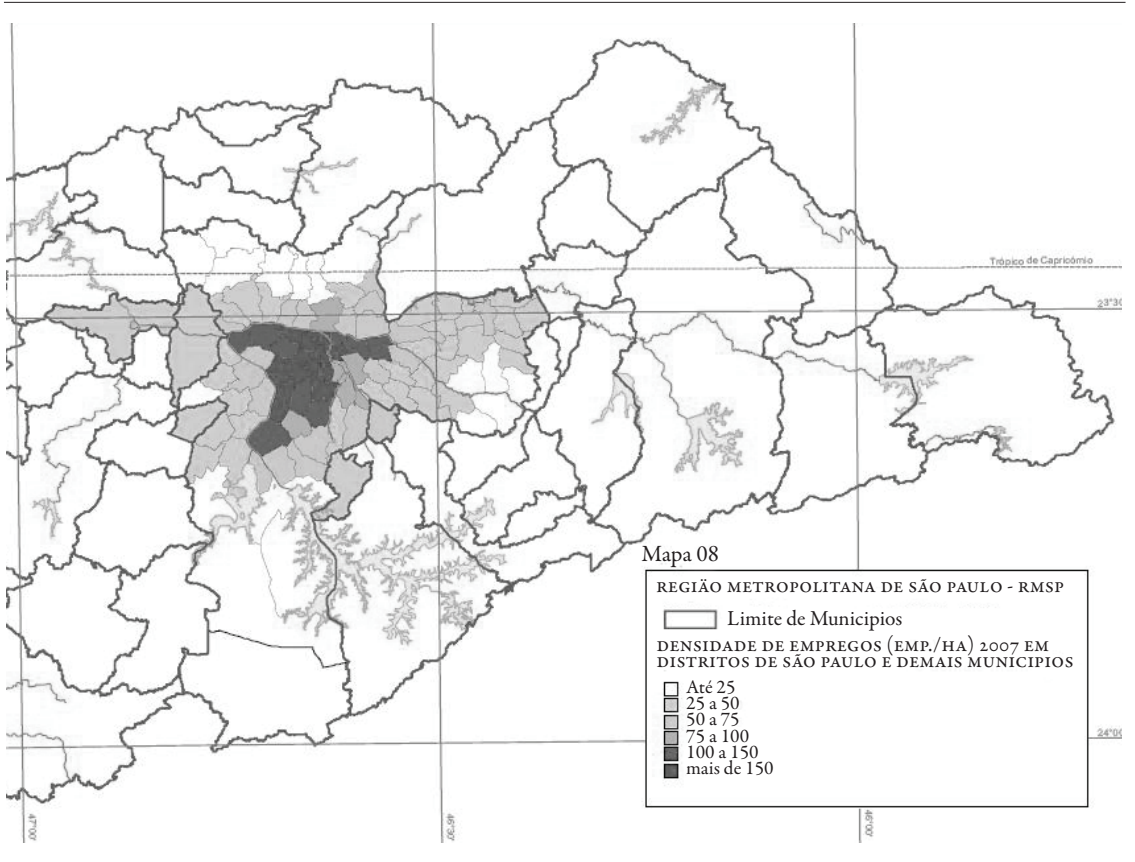

fonte Pesquisa OD 2007 - Síntese das Informaçỗes de Pesquisa Domiciliar, Metrô, 2008.

Outra característica alarmante neste modelo de mobilidade é a violência no trânsito. Segundo a CET, em 2008 morreram 1.463 pessoas no trânsito paulistano. Os atropelamentos foram o tipo de ocorrência mais comum, sendo $27,4 \%$ do total de ocorrências. Foram registrados 7.602 atropelamentos e 658 resultaram em mortes. Ou seja, da mesma forma que os atingidos pela poluição do ar, a maioria dos atingidos pela violência no transito não são os motorizados.

Vasconcelos (1996) demonstra de forma clara como se dá a desigualdade da ocupação de área urbana para quem usa o sistema de transporte coletivo e quem usa o carro em São Paulo. A partir da ocupação estática (veículos parados), o autor analisa a apropriação das áreas urbanas pelo carro particular e pelo ônibus. Como o carro tem 
uma ocupação média de 1,5 pessoas, a área urbana utilizada será de $4,6 \mathrm{~m}^{2}$ por pessoa (considerando um veículo de $7 \mathrm{~m}^{2}$ ). Em um ônibus, o autor usou uma taxa de 0,60 $\mathrm{m}^{2}$ por pessoa. Desta comparação já podemos ver que uma pessoa dentro de um carro ocupa cerca de oito vezes mais espaço urbano que uma pessoa dentro de um ônibus. Se a comparação for feita para os veículos em movimento esta relação pode ir a 10 vezes. Este dado se associa também ao conforto das pessoas. A CET, em conformidade com vários estudos internacionais e com as especificações técnicas da Associação Brasileira de Normas Técnicas (ABNT), utiliza como limite para o nível bom da lotação do ônibus a razão de 6,23 passageiros em pé por metro quadrado de ônibus padrão, excluindo-se deste cálculo as áreas de comando (motorista), degraus, motor, área das portas, catraca e cobrança. ${ }^{3}$ Algumas fontes, como reportagens da agência Globo de notícias ${ }^{4}$ mostram que em horário de pico o metrô de São Paulo chega a ultrapassar 9 pessoas por $\mathrm{m}^{2}$. Apesar de não temos fontes que façam a medição, não é nenhum absurdo dizer que a lotação dos ônibus em horário de pico é similar ao do metrô, com o agravante das condições de aceleração, frenagem e solavancos da viagem.

\section{FIGURA 11 | Comparação do espaço ocupado para o uso do automóvel particular}

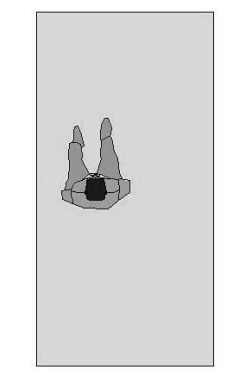

AUTOMóvel

$4,6 \mathrm{~m}^{2}$ por pessoa (ocupação média em São Paulo)

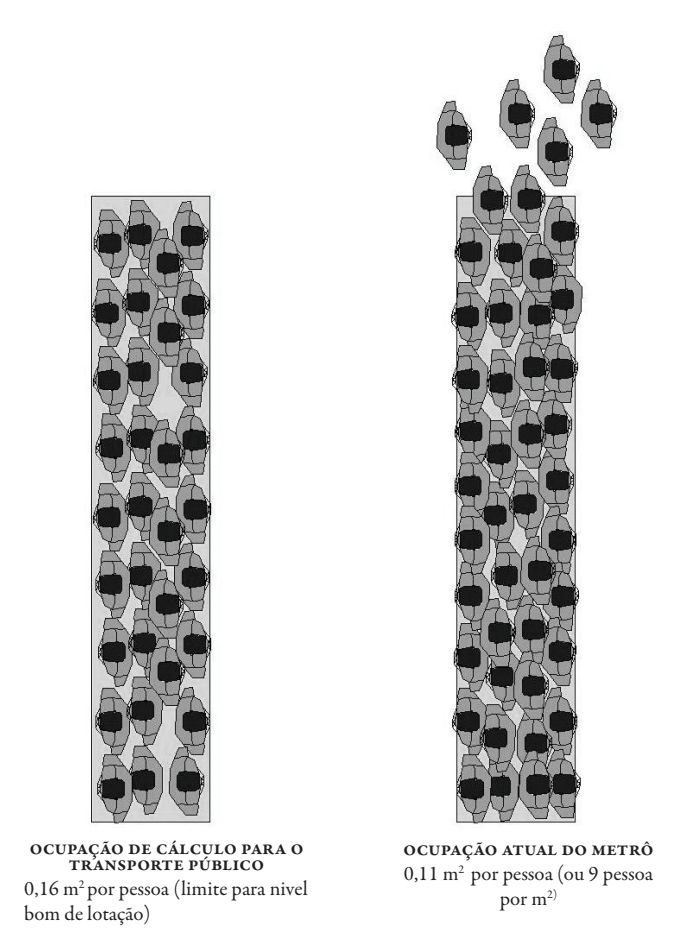

$0,16 \mathrm{~m}^{2}$ por pesson (limite para bom de lotação)

FONTE DADOS DA CET / ABNT / GLOBO E ELABORAÇÃo PRÓPRIA.

3 Para ver o detalhamento desta especificação, consultar a Associação Brasileira de Normas Técnicas (ABNT), Norma Brasileira NBR 15570 .

4 http://video.globo.com/Videos/Player/Noticias/0,,GIM1036392-7823-PASSAGEIROS+RECLAMAM+DE+S UPERLOTACAO+NO+METRO+DE+SAO+PAULO,00.html 
Assim, o que pode parecer um sintoma de crise de todo o sistema de mobilidade da metrópole, a superlotação e o baixo nível de serviço do transporte coletivo não piorou da década de 70 para cá. Alguns setores da metrópole até tiveram uma melhora considerável no que diz respeito ao transporte coletivo. O que acontece agora é que a lentidão nos deslocamentos começou a afetar a todos, mesmo que de forma assimétrica, e só então se passa a enunciar uma situação de crise nos transportes públicos.

\section{$\mathrm{O}$ círculo virtuoso}

A ruptura do círculo vicioso é um dos desafios que se coloca. Nessa busca, consegue-se desenhar, de forma hipotética, um círculo virtuoso de aumento gradativo das formas coletivas de mobilidade. Caso se conquistasse a redução significativa do número de automóveis particulares em circulação, o que aconteceria com o transporte coletivo? Esta redução teria impacto sobretudo no sistema de transporte por ônibus, o principal modo de deslocamento da população paulistana. Possibilitaria o aumento da velocidade de circulação dos ônibus e, conseqüentemente, a redução do tempo de espera. ${ }^{5}$

FIGURA 12 | Círculo virtuoso no padrão de urbanização e sua relação com a mobilidade

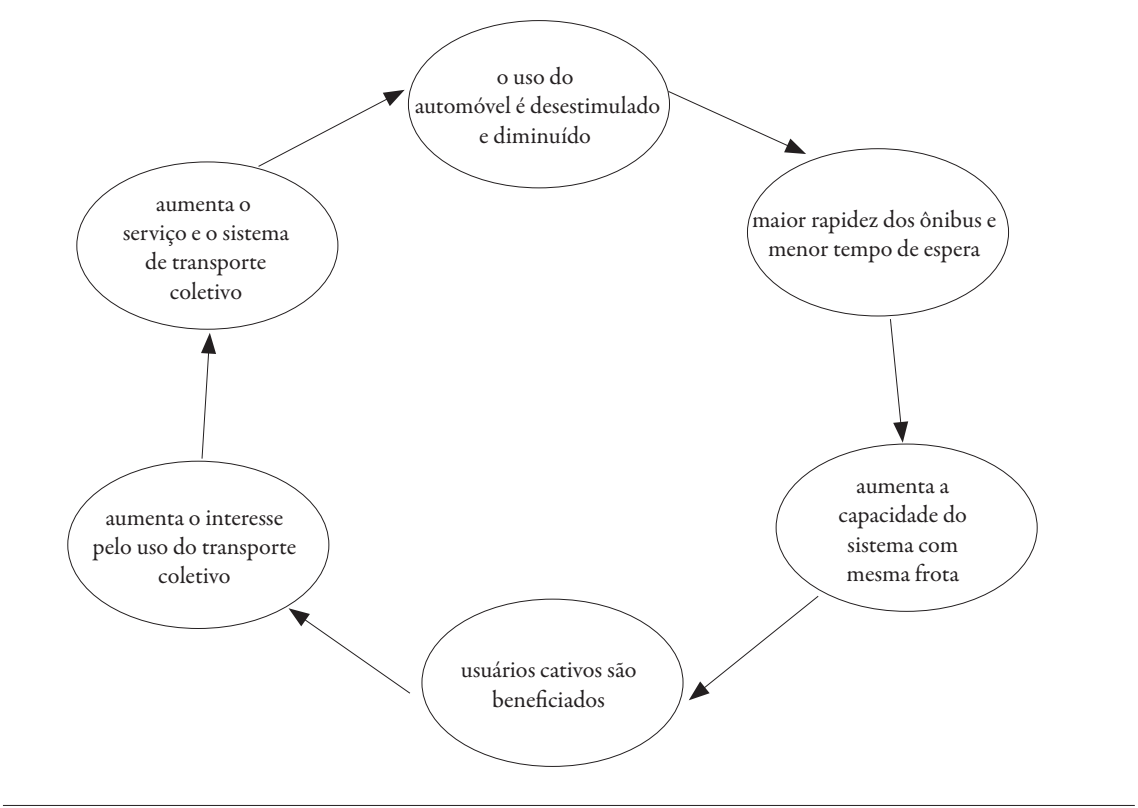

FONTE ELABORAÇÃo PRÓPRIA.

5 Estamos supondo aqui que exista um planejamento racional para o sistema de ônibus. 
Com mais espaço para o transporte coletivo e sem problemas de congestionamento, aliado a uma melhoria no sistema de transporte coletivo, ampliando e integrando outros modos de deslocamento, o circulo virtuoso se desenvolve. $\mathrm{O}$ aumento do nível de serviço do transporte coletivo pode estimular o seu uso por parte dos usuários de automóvel. Com uma maior velocidade do sistema, tem-se um aumento da capacidade de pessoas transportadas. Com uma maior rapidez, menor espera, menor tempo gasto nos trajetos, o custo do transporte diminui, o que acarretaria uma possibilidade de queda na tarifa final. Seria possível ampliar a capacidade de alcance do sistema a áreas ainda não suficientemente atendidas. Com uma melhor condição de nível de serviço e uma menor tarifa, mais pessoas se sentiriam motivadas a usar o sistema de transporte público e deixar de usar o carro. Disto, queremos dizer que a diminuição do número de carros nas ruas é uma condição básica para a diminuição da desigualdade na mobilidade.

Existem algumas implicações a serem consideradas nesta reflexão sobre a diminuição dos carros nas ruas:

- A diminuição dos carros nas ruas requer medidas inibidoras do uso do carro como, por exemplo, a diminuição do espaço disponível para o automóvel e o aumento do espaço destinado ao transporte coletivo e para o pedestre e ciclista;

- As cidades latino-americanas possuem uma estruturação de seu tecido urbano que acarreta o deslocamento de uma multidão de pessoas da periferia residencial em direção ao seu centro pela manhã, e novamente esta multidão se repete em sentido oposto no final do horário de trabalho. Isto implica numa maior dificuldade para implementar conforto e menor tempo gasto com deslocamentos.

- Na urbanização desigual, o investimento em infraestrutura em qualquer localidade reflete num processo de mobilidade residencial, que desloca as famílias de baixa renda para cada vez mais longe das centralidades, num processo contínuo de insuficiência do sistema de transporte e de manutenção da baixa mobilidade das pessoas e acessibilidade à cidade.

O enfrentamento do desafio da mobilidade urbana de qualidade para todos pressupõe uma mudança no tratamento do espaço urbano, que precisaria ser entendido como uma produção social a ser distribuída também socialmente, tanto nos benefícios quanto nos impactos negativos. Assim como o direito à moradia, $\mathrm{o}$ direito à mobilidade urbana precisa se tornar uma demanda social. A abordagem do espaço urbano como um valor de mercado, faz com que uma parcela tenha acesso privilegiado, em função de seu poder aquisitivo. A busca da manutenção dos privilégios agora enuncia o risco de uma condição precária para todos.

\section{Considerações finais}

A cidade não funciona sem seus milhares de deslocamentos diários. Quem tem mais renda, mora nos lugares mais estratégicos, paga o valor gerado pela acessibilidade, e se 
desloca com maior velocidade. Quem tem menos renda, se desloca mais devagar e de forma mais precária e desconfortável. Isto faz com que as pessoas tenham diferentes níveis de acesso à cidade. A busca pelas melhores oportunidades fica restrita a um determinado grupo enquanto a maioria não possui esta capacidade de escolha.

A reversão deste contexto passa pela discussão do acesso ao espaço urbano. No contexto da mobilidade significa valorizar o sistema de transporte público coletivo, as formas não motorizadas de deslocamento e ainda conter o uso do transporte individual. Ainda, a valorização do transporte público precisa se associar a uma política de moradia que possibilite as camadas de menor renda ter direito à moradia nas regióes bem servidas de transporte coletivo, sem que a melhoria da infraestrutura urbana expulse aqueles que não podem pagar pela conseqüente valorização da terra urbana. Não se trata de falta de vontade política, mas da necessidade de redirecionar as prioridades de forma a contemplar o interesse público, ou seja, através da melhor distribuição do espaço urbano. Em síntese, a questão da mobilidade urbana é antes de tudo uma questão de igualdade de direitos no acesso à cidade e aos espaços públicos. O padrão de mobilidade das metrópoles brasileiras se desenvolveu com o pressuposto da desigualdade e a mudança desse quadro demanda o questionamento dessa dinâmica. IEURE

\section{Referências bibliográficas}

Affonso, N. S. N. S. (1985). Chega de Enrolação, Queremos Condução - Movimentos Reivindicativos de Transportes Coletivos em São Paulo, 1979-1983. (Vol. 1). Disertación de Maestría, Facultad de Arquitectura y Urbanismo, Universidad de São Paulo (FAU USP).

Ascher, F. (1995). Métapolis ou l'avenir des villes. París: Odile Jacob.

Avellaneda, P. (2004). Urbanització i transport col-lectiu a les grans ciutats d'Amèrica Llatina. Treballs de la Societat Catalana de Geografia, 57, 33-55. Disponible en http://publicacions.iec.cat /repository/pdf/00000019/00000021.pdf

Caldeira, T. P. do R. (2000). Cidade de muros: crime, segregação e cidadania em São Paulo. São Paulo: Editora 34/Edusp.

Cardoso, C. E. de P. (2008). Análise do Transporte Coletivo Urbano sob a Ótica dos Riscos e Carências Sociais. Tesis de doctorado em Servicios Sociales, Pontificia Universidad Católica de São Paulo.

Cardoso, C. E. de P. (2009a). Distribuição da população na região metropolitana de São Paulo. Engenharia (Instituto de Ingeniería de São Paulo), 596, 116-119. Disponible em http://www. brasilengenharia.com.br/ed/596/Art_Transporte.pdf

Cardoso, C. E. de P. (2009b). Qual o número de veículos de circulam em São Paulo? Trabajo presentado al $17^{\circ}$ Congresso Brasileiro de Transporte e Trânsito ANTP, Curitiba-PR: ANTP.

Dupuy, G. (1995). Les territoires de l'automobile. París: Antropos.

García Palomares, J. C. (2008). Incidencia en la movilidad de los principales factores de un modelo metropolitano cambiante. EURE, 34(101), 5-24. doi: 10.4067/S0250-71612008000100001. 
Harding, G. (1968). The Tragedy of the Commons. Science, 162(1968), 1243-1248. Disponible en http://www.garretthardinsociety.org/articles_pdf/tragedy_of_the_commons.pdf

Miralles, C. (2002). Ciudad y transporte. El binomio imperfecto. Barcelona: Ariel Geografía.

OD Pesquisa Origem Destino 2007. (2008). Sintese das Informações de Pesquisa Domiciliar. São Paulo: Metrô.

Oliveira, F. de (2003). Crítica à razão dualista/ O ornitorrinco. São Paulo: Boitempo.

Santos, M. (1980). A urbanização desigual. Petrópolis: Vozes.

Vasconcellos, E. A. (1996). Transporte urbano nos paises em desenvolvimento: reflexão e propostas. São Paulo: Unidas.

Sites consultados:

www.abnt.org.br

www.agora.uol.com.br

www.antp.org.br

www.cetsp.com.br

www.detran.sp.gov.br

www.folha.uol.com.br

www.gazetadopovo.com.br

www.ippuc.org.br

www.movilidadbogota.gov.co

www.nevusp.org.br

www.onibus.blog.br

www.pr.gov.br/detran

www.setransp.org.br

www.video.globo.com

ww2.prefeitura.sp.gov.br 